\title{
BMJ Open Discontinuing financial incentives for adherence to antipsychotic depot medication: long-term outcomes of a cluster randomised controlled trial
}

\author{
Stefan Priebe, ${ }^{1}$ Stephen A Bremner, ${ }^{2}$ Hana Pavlickova ${ }^{1}$
}

To cite: Priebe $S$, Bremner SA, Pavlickova $\mathrm{H}$. Discontinuing financial incentives for adherence to antipsychotic depot medication: long-term outcomes of a cluster randomised controlled trial. BMJ Open 2016;6:e011673. doi:10.1136/bmjopen-2016011673

- Prepublication history for this paper is available online. To view these files please visit the journal online (http://dx.doi.org/10.1136/ bmjopen-2016-011673).

Received 26 February 2016 Revised 29 July 2016 Accepted 17 August 2016

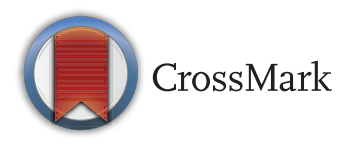

${ }^{1}$ Unit for Social and Community Psychiatry (WHO Collaborating Centre for Mental Health Service Development), Queen Mary University London, London, UK

${ }^{2}$ Division of Primary Care and Public Health, Brighton and Sussex Medical School, Brighton, UK

Correspondence to Stefan Priebe;

s.priebe@qmul.ac.uk

\section{ABSTRACT}

Objectives: In a cluster randomised controlled trial, offering financial incentives improved adherence to antipsychotic depot medication over a 1-year period. Yet, it is unknown whether this positive effect is sustained once the incentives stop.

Methods and analyses: Patients in the intervention and control group were followed up for 2 years after the intervention. Primary and secondary outcomes were assessed at 6 months and 24 months post intervention. Assessments were conducted between September 2011 and November 2014.

Results: After the intervention period, intervention and control groups did not show any statistically significant differences in adherence, neither in the first 6 months ( $71 \%$ and $77 \%$, respectively) nor in the following 18 months $(68 \%, 74 \%)$. There were no statistically significant differences in secondary outcomes, that is, adherence $\geq 95 \%$ and untoward incidents either.

Conclusions: It may be concluded that incentives to improve adherence to antipsychotic maintenance medication are effective only for as long as they are provided. Once they are stopped, adherence returns to approximately baseline level with no sustained benefit.

Trial registration number: ISRCTN77769281; Results.

Poor adherence to antipsychotic maintenance medication is common in patients with psychotic disorders ${ }^{1}$ and linked to a number of negative outcomes. ${ }^{2}$ A range of interventions have been tested to improve adherence to antipsychotic medication, but hardly any has been shown to be effective. For example, so-called Compliance Therapy has explicitly not been recommended by the National Institute of Clinical Excellence. Thus, improving adherence in this patient group remains a challenge in treatment.

Against this background, clinicians in East London tried financial incentives to influence patients' adherence to long-acting injectable antipsychotics (LAIs). They reported positive outcomes in a small
Strengths and limitations of this study

- Patients have been followed up for 24 months post intervention to examine shorter-term and longer-term effects.

- Data were not complete and likely not to be missing at random.

- A number of sensitivity analyses support the main results.

number of patients. ${ }^{3}$ A subsequent focus group study explored the concerns of different stakeholders about the idea of providing financial incentives to increase adherence to antipsychotic medication. While different concerns were raised, there was wide agreement that it would be important to go beyond anecdotal evidence and establish the effectiveness of financial incentives in a rigorous trial. ${ }^{4}$ This led to the design and funding of a cluster randomised controlled trial. ${ }^{5}$

The trial included patients with psychotic disorders treated in secondary mental health teams in the community in England and compared financial incentives with treatment as usual. The findings demonstrated that offering financial incentives of $£ 15$ (US\$22, €17) per LAI over a 1-year period significantly improves adherence to LAIs. ${ }^{6}{ }^{7}$ Adherence already improved within the first 3 months of introducing incentives, and a significant difference with better adherence in patients being offered incentives was sustained over the full 1-year intervention period. ${ }^{8}$ Yet, the question arises as to whether patients maintain improved adherence once incentives have stopped. Would incentives have a lasting positive effect on patients' attitudes and behaviour resulting in ongoing improved adherence levels, or would the incentivised behaviour deteriorate again once the incentives are discontinued? Studies in some health-related behaviours such as smoking 
cessation, ${ }^{9}$ drug abuse ${ }^{10}$ or engagement and retention in HIV treatment and prevention ${ }^{11}{ }^{12}$ suggest that positive changes in response to financial incentives return to baseline, once the incentives have been removed. Other reports indicate that in the long term, incentivised behaviours may even fall below baseline levels, ${ }^{13}{ }^{14}$ therefore having a corruptive effect in the long run.

The aim of this study was to assess long-term outcomes of offering financial incentives to improve adherence to LAIs over 2 years after the incentives had been discontinued.

\section{METHODS}

The FIAT (Financial Incentives for Adherence to Treatment) trial $^{5}$ was a cluster randomised trial with a 1:1 allocation ratio of mental health teams to the intervention or control condition. It included 141 patients with a diagnosis of schizophrenia, schizoaffective disorder or bipolar disorder, whose adherence to LAIs-calculated as the percentage of LAIs received out of those prescribed over a given period of time-in the 4-month screening period was $\leq 75 \%$, were recruited from 73 community teams across England and Wales. Written informed consent was obtained from both patients and consultant psychiatrists/team managers. Teams were randomised to either the intervention group in which patients received $£ 15$ for each LAI, or the control group which were not offered any incentives. Apart from offering incentives in the intervention group, both groups continued with treatment as usual. The intervention lasted for 12 months. All patients were treated in the National Health Service in England where all treatments, including LAIs, were free of charge for all patients all the time.

Recruitment and randomisation procedures, the sample characteristics and the main findings are reported in detail elsewhere. ${ }^{5} 6$ In brief, the baseline mean adherence of $69 \%(\mathrm{SD}=16 \%)$ and $67 \%(\mathrm{SD}=16 \%)$ in the intervention and control group, respectively, improved over the 12-month intervention period to $85 \%$ $(\mathrm{SD}=15 \%)$ and $71 \%(\mathrm{SD}=22 \%)$. The difference between the two groups was statistically significant (adjusted difference in means $(\beta)=11.5 \%, 95 \%$ CI $(3.9 \%$ to $19.0 \%)$, $\mathrm{p}=0.0003)$. Patients in the intervention group also had a significantly better subjective quality of life at the end of the 1-year period.

Patients were followed up after the end of the intervention for another 24 months. Outcomes were assessed based on medical records for two separate intervals, that is, the first 6 months and the subsequent 18 months, to distinguish between shorter-term and longer-term outcomes. The assessments for the first 6 months after the end of the intervention were conducted between September 2011 and May 2013, and assessments for the subsequent 18 months between March 2013 and November 2014.

\section{Primary and secondary outcomes at follow-up}

Primary outcome was adherence to LAIs, again calculated as the percentage of LAIs received out of those prescribed over the relevant time periods, that is, over 6 months and over an additional 18 months post intervention. Secondary outcomes were LAI adherence $\geq 95 \%$, psychiatric hospital admissions and untoward incidents including police arrest, violent acts and suicide attempts. As in the analysis of the effects during the intervention period, in the calculation, adherence periods spent in hospitals were not considered.

\section{Statistical analyses}

\section{Primary outcome}

A linear mixed effects regression model with a random effect for the clinical treatment team in which patients received care was used to examine the differences in adherence levels during the 6-month follow-up data. We adjusted for the adherence measure at baseline, MINI International Neuropsychiatric Interview score of team catchment area at randomisation ${ }^{15}$ and the average prescription cycle of LAIs during the baseline period, which depending on the type of medication and specific prescription varied between every week and every 4 weeks.

A simple linear regression model including only a fixed effect for allocation was fitted to the additional follow-up data for the 18 months period between month 7 and month 24. As the intraclass correlation for adherence was negative $(-0.05)$, we did not include a random effect for team. Various sensitivity analyses were conducted: (A) setting adherence of patients with reports of refusing medication to $0 \%$, (B) setting adherence of patients transferred to primary care to $100 \%$ and (C) including patients with less than 4 months' adherence data during the 6 month follow-up period.

\section{Secondary outcomes}

For the initial follow-up period of 6 months and the subsequent 18 months, achieving at least $95 \%$ adherence was analysed using mixed effects logistic regression models as described for the primary outcome analysis. This adherence level was chosen to reflect quasi complete adherence. In line with the statistical analyses plan, hospital admissions and adverse events were summarised descriptively at both time intervals due to insufficient power to detect any differences between groups.

\section{RESULTS}

The flow of the participants throughout the duration of the study and socio-demographic and clinical characteristics are presented in the CONSORT diagram (figure 1) and table 1 , respectively. Of the 141 randomised patients, 9 were lost to the 6-month follow-up. Of the 132 remaining, the primary outcome could be defined for 106 patients. However, only 99 (58 intervention patients and 41 control patients) had the primary outcome defined at both baseline and 6-month follow-up. At 24 months post intervention, 131 patients remained: additional five patients were lost from the 6-month follow-up, while four patients lost to 6-month 
Figure 1

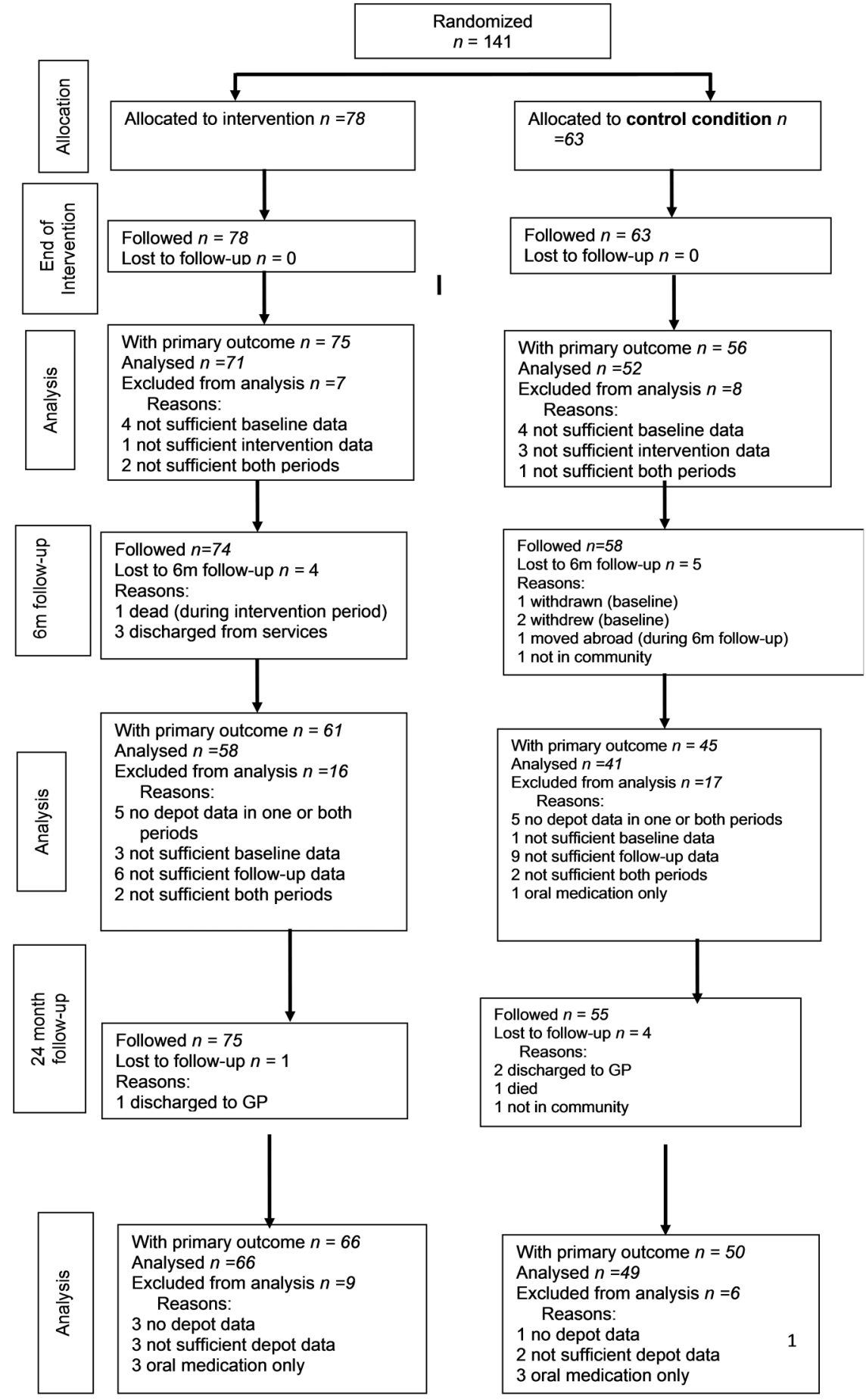

follow-up returned to the study (ie, two patients, who had moved away, and two who had been out of the community or discharged to primary care). The primary outcome could be defined for 116 patients (ie, for 66 intervention patients and 50 control patients). This equates to overall follow-up rates of $75.2 \%$ after 6 months and $82.3 \%$ after 24 months.

As we have previously shown, less frequent cycles were linked with better adherence. ${ }^{16}$ The changes in treatment cycles throughout the study and associated adherence levels are presented in table 2 and table 3, respectively.
The presented descriptive data point to a greater transitioning to less frequent cycles in the control group than in the intervention group throughout the study.

Although the study protocol did not influence whether or not incentives in the intervention group would be continued after the 1-year study period, in practice no patient was offered further incentives by their care teams.

\section{Primary outcome}

To aid transparency in the change in outcomes throughout the study, table 4 presents the primary outcome at 


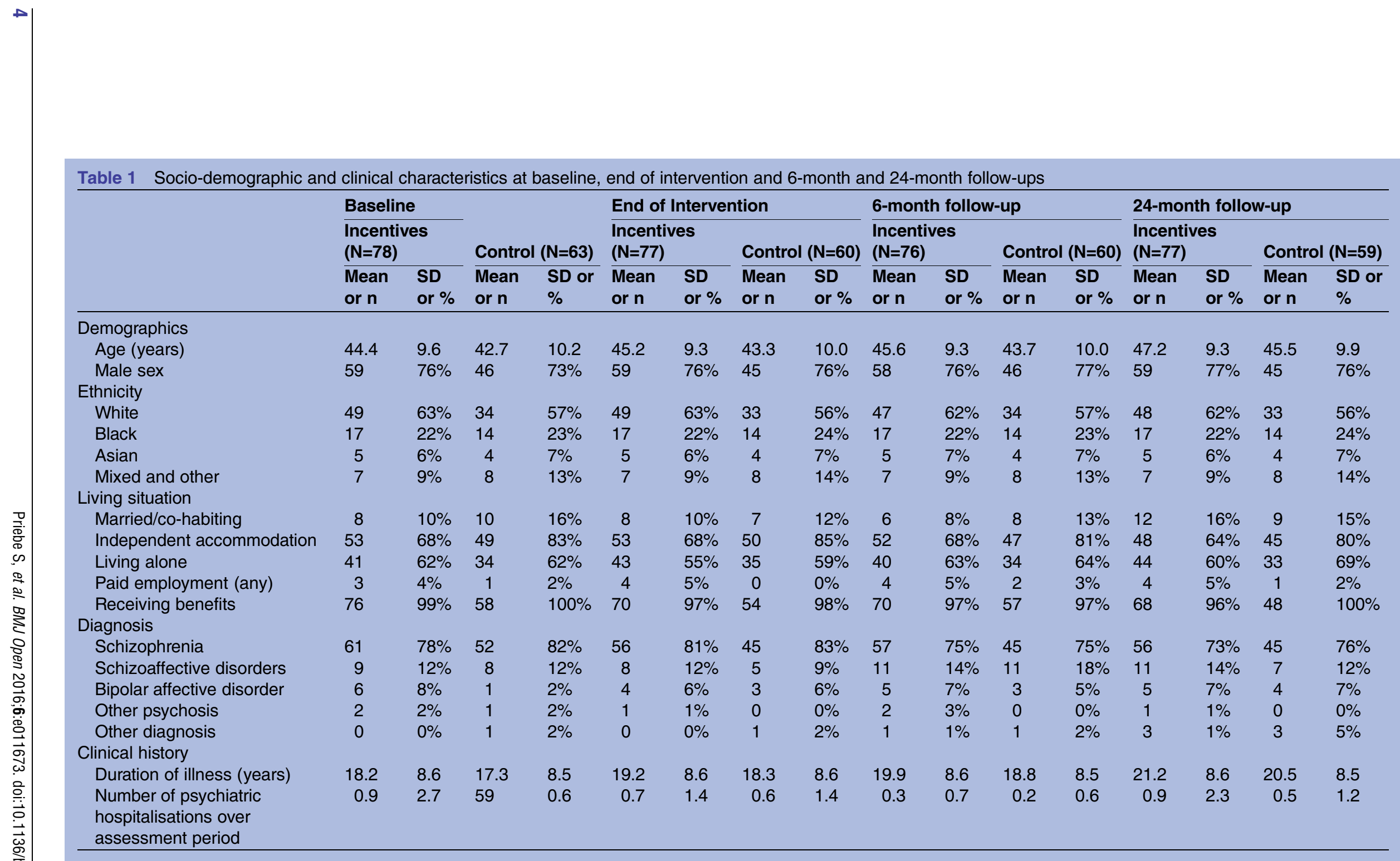


Table 2 Treatment cycles during baseline, intervention period and during the two follow-up periods

\begin{tabular}{|c|c|c|c|c|c|c|c|c|c|c|c|c|c|c|c|c|}
\hline \multirow[b]{3}{*}{ Depot cycle } & \multicolumn{4}{|c|}{ Baseline } & \multicolumn{4}{|c|}{ End of Intervention } & \multicolumn{4}{|c|}{ 1-6-month follow-up } & \multicolumn{4}{|c|}{ 7-24-month follow-up } \\
\hline & \multicolumn{2}{|c|}{ Incentives } & \multicolumn{2}{|c|}{ Control } & \multicolumn{2}{|c|}{ Incentives } & \multicolumn{2}{|c|}{ Control } & \multicolumn{2}{|c|}{ Incentives } & \multicolumn{2}{|c|}{ Control } & \multicolumn{2}{|c|}{ Incentives } & \multicolumn{2}{|c|}{ Control } \\
\hline & $\mathbf{N}$ & $\%$ & $\overline{\mathbf{N}}$ & $\%$ & $\overline{\mathbf{N}}$ & $\%$ & $\overline{\mathbf{N}}$ & $\%$ & $\mathbf{N}$ & $\%$ & $\mathbf{N}$ & $\%$ & $\mathbf{N}$ & $\%$ & $\mathbf{N}$ & $\%$ \\
\hline $1 / 52$ & 4 & 5.6 & 3 & 5.5 & 2 & 2.7 & 1 & 1.8 & 2 & 3.3 & 3 & 6.7 & 3 & 4 & 1 & 2 \\
\hline $2 / 52$ & 50 & 69.4 & 34 & 61.8 & 51 & 68.0 & 29 & 51.8 & 38 & 62.3 & 20 & 32.8 & 44 & 63 & 24 & 44 \\
\hline $3 / 52$ & 5 & 6.9 & 2 & 3.6 & 4 & 5.3 & 3 & 5.4 & 4 & 6.6 & 2 & 4.5 & 3 & 7 & 1 & 2 \\
\hline $4 / 52$ & 12 & 16.7 & 13 & 23.6 & 13 & 17.3 & 18 & 32.1 & 11 & 18.0 & 13 & 28.9 & 11 & 16 & 20 & 37 \\
\hline Variable & 1 & 1.4 & 3 & 5.5 & 5 & 6.7 & 5 & 8.9 & 6 & 9.8 & 7 & 15.6 & 7 & 10 & 8 & 15 \\
\hline Total & 72 & 100 & 55 & 100 & 75 & 100 & 56 & 100 & 61 & 100 & 45 & 100 & 70 & 100 & 54 & 100 \\
\hline
\end{tabular}

Table 3 Adherence by treatment cycle at baseline, during the intervention period and during follow-up periods

\begin{tabular}{|c|c|c|c|c|c|c|c|c|c|c|c|c|c|c|c|c|}
\hline \multirow[b]{3}{*}{$\begin{array}{l}\text { Treatment } \\
\text { cycle }\end{array}$} & \multicolumn{4}{|c|}{ Baseline period $(\mathrm{N}=123)$} & \multicolumn{4}{|c|}{ Intervention period $(\mathrm{N}=123)$} & \multicolumn{4}{|c|}{ 1-6-month follow-up $(\mathrm{N}=110)$} & \multicolumn{4}{|c|}{ 7-24-month follow-up $(\mathrm{N}=110)$} \\
\hline & \multicolumn{2}{|c|}{$\begin{array}{l}\text { Incentives } \\
(\mathrm{N}=71)\end{array}$} & \multicolumn{2}{|c|}{$\begin{array}{l}\text { Control } \\
(\mathrm{N}=52)\end{array}$} & \multicolumn{2}{|c|}{$\begin{array}{l}\text { Incentives } \\
(\mathrm{N}=71)\end{array}$} & \multicolumn{2}{|c|}{$\begin{array}{l}\text { Control } \\
(\mathrm{N}=52)\end{array}$} & \multicolumn{2}{|c|}{$\begin{array}{l}\text { Incentives } \\
(\mathrm{N}=66)\end{array}$} & \multicolumn{2}{|c|}{$\begin{array}{l}\text { Control } \\
(\mathrm{N}=54)\end{array}$} & \multicolumn{2}{|c|}{$\begin{array}{l}\text { Incentives } \\
(\mathrm{N}=66)\end{array}$} & \multicolumn{2}{|c|}{$\begin{array}{l}\text { Control } \\
(\mathrm{N}=54)\end{array}$} \\
\hline & $\mathbf{N}$ & $\begin{array}{l}\text { Mean } \\
\text { adherence } \\
(\%)\end{array}$ & $\mathbf{N}$ & $\begin{array}{l}\text { Mean } \\
\text { adherence } \\
(\%)\end{array}$ & $\mathbf{N}$ & $\begin{array}{l}\text { Mean } \\
\text { adherence }\end{array}$ & $\mathbf{N}$ & $\begin{array}{l}\text { Mean } \\
\text { adherence } \\
(\%)\end{array}$ & $\mathbf{N}$ & $\begin{array}{l}\text { Mean } \\
\text { adherence } \\
(\%)\end{array}$ & $\mathbf{N}$ & $\begin{array}{l}\text { Mean } \\
\text { adherence } \\
(\%)\end{array}$ & $\mathbf{N}$ & $\begin{array}{l}\text { Mean } \\
\text { adherence } \\
(\%)\end{array}$ & $\mathbf{N}$ & $\begin{array}{l}\text { Mean } \\
\text { adherence } \\
(\%)\end{array}$ \\
\hline $1 / 52$ & 2 & 54 & 1 & 45 & 2 & 82 & 1 & 49 & 3 & 76 & 3 & 64 & 3 & 78 & 1 & 85 \\
\hline $2 / 52$ & 49 & 67 & 27 & 68 & 49 & 83 & 27 & 74 & 41 & 71 & 23 & 74 & 41 & 67 & 24 & 73 \\
\hline $3 / 52$ & 4 & 76 & 3 & 66 & 4 & 97 & 3 & 44 & 4 & 77 & 2 & 83 & 5 & 74 & 1 & 77 \\
\hline $4 / 52$ & 12 & 76 & 16 & 66 & 12 & 92 & 16 & 73 & 13 & 71 & 20 & 74 & 11 & 66 & 18 & 73 \\
\hline $5 / 52$ & $\mathrm{n} / \mathrm{a}$ & $\mathrm{n} / \mathrm{a}$ & $\mathrm{n} / \mathrm{a}$ & $\mathrm{n} / \mathrm{a}$ & $\mathrm{n} / \mathrm{a}$ & $\mathrm{n} / \mathrm{a}$ & $\mathrm{n} / \mathrm{a}$ & $\mathrm{n} / \mathrm{a}$ & 1 & 71 & 0 & $\mathrm{n} / \mathrm{a}$ & $\mathrm{n} / \mathrm{a}$ & $\mathrm{n} / \mathrm{a}$ & $\mathrm{n} / \mathrm{a}$ & $\mathrm{n} / \mathrm{a}$ \\
\hline Variable cycle & 4 & 60 & 5 & 62 & 4 & 72 & 5 & 72 & 4 & 59 & 6 & 87 & 6 & 68 & 6 & 75 \\
\hline
\end{tabular}


Table 4 Primary and secondary outcomes at baseline, end of intervention and 6-month and 24-month follow-ups

\begin{tabular}{|c|c|c|c|c|c|c|c|c|c|}
\hline & \multirow[b]{2}{*}{ Period } & \multicolumn{2}{|c|}{ Incentives } & \multicolumn{2}{|c|}{ Control } & \multirow[b]{2}{*}{$\begin{array}{l}\text { Type of effect } \\
\text { estimate }\end{array}$} & \multirow[b]{2}{*}{$\begin{array}{l}\text { Adjusted effect estimate } \\
\text { (intervention vs control) }\end{array}$} & \multirow[b]{2}{*}{ p Value } & \multirow[b]{2}{*}{ ICC } \\
\hline & & $\begin{array}{l}\mathrm{n}^{\star} \\
74 \dagger / \\
75 \ddagger \\
\end{array}$ & $\begin{array}{l}\text { Number (\%) or } \\
\text { means (SD) }\end{array}$ & $\begin{array}{l}n^{\star} \\
58 \dagger / \\
56 \ddagger \\
\end{array}$ & $\begin{array}{l}\text { Number (\%) or } \\
\text { means (SD) }\end{array}$ & & & & \\
\hline \multicolumn{10}{|l|}{ Primary outcome } \\
\hline \multirow{4}{*}{$\begin{array}{l}\text { Adherence (percentage) } \\
\text { to depot medication }\end{array}$} & Baseline & 72 & $69 \%(16 \%)$ & 55 & $67 \%(16 \%)$ & & & & \\
\hline & 12-month intervention & 75 & $85 \%(15 \%)$ & 56 & $71 \%(22 \%)$ & $\begin{array}{l}\text { Difference in } \\
\text { means }\end{array}$ & $11.5 \%(3.9 \% \text { to } 19.0 \%)^{\star \star}$ & 0.0003 & 0.28 \\
\hline & 1-6-month follow-up & 58 & $70 \%(24 \%)$ & 41 & $77 \%(19 \%)$ & $\begin{array}{l}\text { Difference in } \\
\text { means } \|\end{array}$ & $-7.4 \%(-17.0 \%$ to $2.1 \%)$ & 0.127 & 0.175 \\
\hline & 7-24-month follow-up & 66 & $68 \%(21 \%)$ & 50 & $74 \%(19 \%)$ & $\begin{array}{l}\text { Difference in } \\
\text { means }\end{array}$ & $-5.7 \%(-13.1 \%$ to $1.7 \%)$ & 0.130 & $\mathrm{n} / \mathrm{a}$ \\
\hline \multicolumn{10}{|l|}{ Secondary outcomes } \\
\hline \multirow{4}{*}{$\begin{array}{l}\text { Achieving at least } 95 \% \\
\text { adherence vs not }\end{array}$} & Baseline & 72 & $5(7 \%)$ & 55 & $1(2 \%)$ & & & & \\
\hline & 12-month intervention & 75 & $21(28 \%)$ & 56 & $3(5 \%)$ & ORף & 8.21 (2.00 to 33.67 ) & 0.003 & 0.04 \\
\hline & 1-6-month follow-up & 66 & $5(8 \%)$ & 54 & $9(17 \%)$ & ORף & $0.42(0.11$ to 1.61$)$ & 0.205 & $<0.001$ \\
\hline & 7-24-month follow-up & 66 & $4(6 \%)$ & 50 & $5(10 \%)$ & OR & 0.42 (0.06 to 3.02$)$ & 0.392 & 0.42 \\
\hline \multirow{4}{*}{$\begin{array}{l}\text { At least one psychiatric } \\
\text { hospital admission }\end{array}$} & Baseline & 78 & $14(19 \%)$ & 60 & $10(17 \%)$ & & & & \\
\hline & 12-month intervention & 78 & 15 (19\%) & 59 & $14(24 \%)$ & & & & \\
\hline & 1-6-month follow-up & 74 & $15(20 \%)$ & 58 & $8(14 \%)$ & & & & \\
\hline & 7-24-month follow-up & 77 & $24(31 \%)$ & 60 & $10(17 \%)$ & & & & \\
\hline \multirow{4}{*}{$\begin{array}{l}\text { At least one suicide } \\
\text { attempt vs none }\end{array}$} & Baseline & 78 & $9(12 \%)$ & 59 & $7(12 \%)$ & & & & \\
\hline & 12-month intervention & 77 & $8(10 \%)$ & 58 & $4(7 \%)$ & & & & \\
\hline & 1-6-month follow-up & 73 & $3(4 \%)$ & 58 & $3(5 \%)$ & & & & \\
\hline & 7-24-month follow-up & 75 & $5(7 \%)$ & 58 & $3(5 \%)$ & & & & \\
\hline \multirow{4}{*}{$\begin{array}{l}\text { At least one violent } \\
\text { incident vs none }\end{array}$} & Baseline & 77 & $15(20 \%)$ & 60 & $10(17 \%)$ & & & & \\
\hline & 12-month intervention & 77 & $10(13 \%)$ & 58 & $7(12 \%)$ & & & & \\
\hline & 1-6-month follow-up & 73 & $4(6 \%)$ & 58 & $3(5 \%)$ & & & & \\
\hline & 7-24-month follow-up & 75 & $11(15 \%)$ & 58 & $7(12 \%)$ & & & & \\
\hline \multirow{4}{*}{$\begin{array}{l}\text { At least one police arrest } \\
\text { vs none }\end{array}$} & Baseline & 77 & $13(18 \%)$ & 60 & $9(16 \%)$ & & & & \\
\hline & 12-month intervention & 77 & $10(13 \%)$ & 60 & $10(17 \%)$ & & & & \\
\hline & 1-6-month follow-up & 73 & $6(8 \%)$ & 58 & $3(5 \%)$ & & & & \\
\hline & 7-24-month follow-up & 75 & $14(19 \%)$ & 58 & $10(17 \%)$ & & & & \\
\hline \multicolumn{10}{|c|}{$\begin{array}{l}{ }^{*} \mathrm{n} \text { is the number of patients in either group with both a baseline and follow-up period for the specified outcome. } \\
\text { †Number of patients during } 6 \text {-month follow-up. Excludes } 9 \text { patients on whom no data were collected during the } 6 \text {-month follow-up period: } 2 \text { who withdrew immediately after randomisation and } 1 \\
\text { who was withdrawn as was not being prescribed depot medication, } 1 \text { who died during the intervention period, } 2 \text { who were discharged during the intervention period, } 1 \text { who was discharged } \\
\text { during the } 6 \text {-month follow-up period, } 1 \text { who moved abroad during follow-up and } 1 \text { who was out of the community for all of the follow-up period. } \\
\text { fNumber of patients during } 24 \text {-month follow-up. Excludes } 4 \text { patients who were lost to follow-up before the start of the } 6 \text {-month follow-up period. Of the remaining } 137 \text { patients, } 5 \text { were lost during } \\
\text { the } 6 \text {-month follow-up and a further } 5 \text { were lost to follow-up during the final phase of the study. Four patients lost during the } 6 \text {-month follow-up returned to the study. } \\
\text { qEach model was adjusted for baseline measure of outcome, MINI International Neuropsychiatric Interview score category (low vs high) and average treatment cycle during baseline, and } \\
\text { includes a random effect for team. } \\
\text { ICC, Intraclass Correlation Coefficient. }\end{array}$} \\
\hline
\end{tabular}


all assessment periods. Mean adherence calculated on all available cases for the 6-month and further 18-month follow-up periods was $71 \%$ and $68 \%$ in the intervention group, and $78 \%$ and $74 \%$ in the control group. The difference between the groups was not statistically significant at either time point (adjusted means difference for first 6 months $-7.4 \%, 95 \% \mathrm{CI}-17.0$ to $2.1, \mathrm{p}=0.175$; for following 18 months -5.7 , 95\% CI $-13.1 \%$ to $1.7 \%$, $\mathrm{p}=0.130$ ).

The results of the sensitivity analyses were very similar to the main analyses, that is, all reflected slightly lower adherence in the intervention group with the difference not being statistically significant (table 5 ).

\section{Secondary outcomes}

The effect of financial incentives on secondary outcomes through the study is presented in table 5. The percentage of patients achieving at least $95 \%$ adherence during the 6-month and further 18-month follow-up was not significantly different between groups (adjusted OR at 6 months $=0.42,95 \%$ CI 0.11 to $1.61, \mathrm{p}=0.205$; and at 24 months $=0.42,95 \%$ CI 0.06 to $3.02, \mathrm{p}=0.392$ ). No substantial differences were noted in adverse events in either follow-up period. However, there were a higher number of hospital admissions in the intervention group in 6-month and 24-month follow-ups, a difference which, according to our prespecified analysis plan, was shown with only descriptive statistics.

\section{DISCUSSION}

Once financial incentives stop after a year, adherence levels to LAIs return approximately to the levels at the time before the intervention had started. While the positive effect of incentives was consistent for the 1-year intervention period, the return to baseline levels occurs in the first 6 months and remains stable for the 2 years that patients were followed up in this study. Adherence levels in the intervention group were even lower than in the control group, but the differences are small and not statistically significant. The findings suggest that improvements are not sustained, but do not provide any evidence for a negative long-term impact-so called 'crowding out'-either. No statistically significant differences were found for the secondary outcomes, although descriptively patients in the intervention group showed an increased number of hospital admissions in comparison to the control group in both follow-up periods.

\section{Strengths and limitations}

The study followed patients up over a 2-year period after the 1-year intervention. No patient in the intervention group had been offered further incentives after the research determined 1-year intervention period. One may wonder whether stopping incentives for all patients despite significant improvements in adherence and quality of life of some patients was clinically-and ethically-appropriate. Yet, the fact that no patient continued to be offered incentives simplified the evaluation of long-term effects as there was no variation in the duration of the intervention. The findings for the first 6 months and the subsequent 18 months were similar, suggesting a consistent effect over time.

The follow-up study also has several limitations. The most important is that follow-up data were not complete. While the 1-year outcome data in the original 1-year study had only a small number of dropouts, the dropout rate substantially increased during the 2-year follow-up period. While the overall follow-up rates of $75 \%$ and $82 \%$ may be regarded as reasonable, missing data may be a particular problem in this type of study. Missing data were due to a number of reasons, such as referral of the patient to primary care or a complete loss of contact with services. These reasons may reflect different scenarios and outcomes. In any case, missing data are unlikely to have occurred at random. It is impossible to assess with certainty whether and, if so, how this selection influenced the results. However, sensitivity analyses with extreme assumptions about the missing data did not alter the findings. Adherence rates were also associated with the prescription cycle which changed

Table 5 Sensitivity analysis of primary outcome at the two follow-up periods

\begin{tabular}{|c|c|c|c|c|c|c|c|c|}
\hline \multirow[b]{2}{*}{ Analysis population } & \multicolumn{4}{|c|}{ 1-6-month follow-up } & \multicolumn{4}{|c|}{ 7-24-month follow-up } \\
\hline & $\mathbf{N}$ & $\begin{array}{l}\text { Difference } \\
\text { in mean } \\
\text { adherence }\end{array}$ & $95 \% \mathrm{Cl}$ & p Value & $\mathbf{N}$ & $\begin{array}{l}\text { Difference } \\
\text { in mean } \\
\text { adherence }\end{array}$ & $95 \% \mathrm{Cl}$ & p Value \\
\hline $\begin{array}{l}\text { Main analysis: all participants with } \\
\geq 4 \text { months' depot data }\end{array}$ & 108 & $-6.2 \%$ & $-13.1 \%$ to $0.7 \%$ & 0.078 & 116 & $-5.7 \% *$ & $-13.1 \%$ to $1.7 \%$ & 0.130 \\
\hline $\begin{array}{l}\text { All participants as above, setting } \\
\text { adherence to } 100 \% \text { for those } \\
\text { discharged to GP }\end{array}$ & 130 & $-5.0 \%$ & $-14.7 \%$ to $4.7 \%$ & 0.316 & 119 & $-6.2 \%$ * & $-13.6 \%$ to $1.1 \%$ & 0.097 \\
\hline $\begin{array}{l}\text { All participants as above but setting } \\
\text { adherence to } 0 \% \text { for refusers }\end{array}$ & 112 & $-4.9 \%$ & $-14.3 \%$ to $4.2 \%$ & 0.312 & 124 & $-6.4 \% \dagger$ & $-15.0 \%-2.1 \%$ & 0.142 \\
\hline
\end{tabular}


differently in the two groups with a tendency towards longer cycles in the control group, and longer cycles were overall associated with better adherence rates. Yet, the changes within each group were inconsistent and the numbers too small for a separate analysis of subgroups with specific patterns of changes. Further limitations are that patients were not interviewed again, so that we did not assess effects and side effects of the medication, and could not explore whether the significant advantages of the intervention group in subjective quality of life were maintained or also lost during the follow-up; and that the study was not powered to establish whether the small adherence differences in favour of the control group were statistically significant or to detect statistically significant differences in rarer secondary outcomes such as rehospitalisations.

\section{Implications}

The findings are consistent with previous literature that suggests that offering financial incentives may improve health-related behaviours for as long as they are provided. This applies to both general ${ }^{17}$ and mental health populations. ${ }^{18}{ }^{19}$ While a recent systematic review on the effectiveness of financial incentives on health-related behaviours including smoking cessation, diet, reduced alcohol consumption and physical activity suggested that positive effects might last for a short period (ie, 3 months) beyond the provision of incentives, ${ }^{20}$ there is strong evidence suggesting that these benefits are not sustained and that there are no positive long-term effects. ${ }^{9} 1019$ The findings of our study show that this applies to improved adherence to antipsychotic maintenance medication too.

The FIAT study as a whole has provided clear findings with direct clinical implications. The follow-up study complements the picture of the main trial. The number of patients in the NHS in England who fulfil the inclusion criteria of this study has been estimated to be lower than 1800 at one time. ${ }^{6}$ For these patients, financial incentives improve adherence to antipsychotic depot medication for as long as they are offered, at least for a full year. However, the potential hope that patients with improved adherence may have experienced sufficient benefits to maintain the improved adherence level even when incentives are stopped seems to be unjustified. At least on a group level, there is no evidence for such sustained benefit. On the other hand, there is no evidence either that offering incentives would lead to negative long-term effects once they are stopped. When financial incentives are considered to improve adherence to antipsychotic depot medication, potential positive or negative long-term effects may not be a main criterion.

Contributors SP: conceived the original study design and its development, contributed to data interpretation, and drafting of the manuscript. SAB: contributed to the data analyses, data interpretation and drafting of the manuscript. HP: contributed to data acquisition, interpretation and drafting of the manuscript.
Funding This work was supported by the National Institute for Health Research, Health Technology Assessment (NIHR HTA) programme (project No: $07 / 60 / 43$ ).

Disclaimer The views and opinions expressed therein are those of the authors and do not necessarily reflect those of the funder.

Competing interests None declared.

Patient consent Obtained.

Ethics approval This study was approved by the NRES Ealing and West London Research Ethics Committee (reference number 09/H0710/35).

Provenance and peer review Not commissioned; externally peer reviewed.

Data sharing statement Anonymised data can be obtained from the corresponding author.

Open Access This is an Open Access article distributed in accordance with the terms of the Creative Commons Attribution (CC BY 4.0) license, which permits others to distribute, remix, adapt and build upon this work, for commercial use, provided the original work is properly cited. See: http:// creativecommons.org/licenses/by/4.0/

\section{REFERENCES}

1. Thomas $P$. The stable patient with schizophrenia--from antipsychotic effectiveness to adherence. Eur Neuropsychopharmacol 2007;17 (Suppl 2):S115-22.

2. Hong J, Reed C, Novick D, et al. Clinical and economic consequences of medication non-adherence in the treatment of patients with a manic/mixed episode of bipolar disorder: Results from the European Mania in Bipolar Longitudinal Evaluation of Medication (EMBLEM) Study. Psychiatry Res 2011;190:110-14.

3. Claassen D, Ascoli M, Berhe T, et al. Research on mental disorders and their care in immigrant populations: a review of publications from Germany, Italy and the UK. Eur Psych 2005;20:540-9.

4. Priebe S, Sinclair J, Burton A, et al. Acceptability of offering financial incentives to achieve medication adherence in patients with severe mental illness: a focus group study. J Med Ethics 2010;36:463-8.

5. Priebe S, Burton A, Ashby D, et al. Financial incentives to improve adherence to anti-psychotic maintenance medication in non-adherent patients-a cluster randomised controlled trial (FIAT). BMC Psych 2009;9:61.

6. Priebe S, Yeeles K, Bremner S, et al. Effectiveness of financial incentives to improve adherence to maintenance treatment with antipsychotics: cluster randomised controlled trial. Br Med J 2013;347: 55847

7. Henderson C, Knapp M, Yeeles K, et al. Cost-effectiveness of financial incentives to promote adherence to depot antipsychotic medication: economic evaluation of a cluster-randomised controlled trial. PLOS ONE 2015;10:e0138816.

8. Wu R, López-Correa C, Rutkowski JL, et al. Germline mutations in NF1 patients with malignancies. Genes Chromosomes Cancer 1999;26:376-80.

9. Volpp KG, Troxel AB, Pauly MV, et al. A randomized, controlled trial of financial incentives for smoking cessation. $N$ Engl J Med 2009;360:699-709.

10. Roll JM, Chermack ST, Chudzynski JE. Investigating the use of contingency management in the treatment of cocaine abuse among individuals with schizophrenia: a feasibility study. Psychiatry Res 2004;125:61-4.

11. Yotebieng $\mathrm{M}$, Thirumurthy $\mathrm{H}$, Moracco KE, et al. Conditional cash transfers and uptake of and retention in prevention of mother-to-child HIV transmission care: a randomised controlled trial. Lancet HIV 2016;3:e85-93.

12. Bassett IV, Wilson D, Taaffe J, et al. Financial incentives to improve progression through the HIV treatment cascade. Curr Opin HIV and AIDS 2015;10:451-63.

13. Gneezy U, Meier S, Rey-Biel P. When and why incentives (Don't) work to modify behavior. J Econ Perspect 2011;25:1-21.

14. Deci EL, Koestner R, Ryan RM. A meta-analytic review of experiments examining the effects of extrinsic rewards on intrinsic motivation. Psychol Bull 1999;125:627-68.

15. Glover GR, Leese M, McCrone P. More severe mental illness is more concentrated in deprived areas. $\mathrm{Br} J$ Psychiatry 1999;175:544-8.

16. Pavlickova H, Bremner SA, Priebe S. The effect of financial incentives on adherence to antipsychotic depot medication: does it change over time? J Clin Psychiatry 2015;76:1478-034. 
17. Giuffrida A, Torgerson DJ. Should we pay the patient? Review of financial incentives to enhance patient compliance. Br Med $J$ 1997;315:703-7.

18. Tidey JW. Using incentives to reduce substance use and other health risk behaviors among people with serious mental illness. Prev Med 2012;55:S54-60.
19. Burton A, Marougka S, Priebe S. Do financial incentives increase treatment adherence in people with severe mental illness? A systematic review. Epidemiol Psichiatr Soc 2010;19:233-42.

20. Mantzari E, Vogt F, Shemilt I, et al. Personal financial incentives for changing habitual health-related behaviors: a systematic review and meta-analysis. Prev Med 2015;75:75-85. 